Pathophysiology of Haemostasis and Thrombosis
Pathophysiol Haemost Thromb 2003;33:157-163 DOI: $10.1159 / 000077824$
Received: July 24, 2003

Accepted after revision: January 14, 2004

\title{
Factor V Gene (1691 A and 4070G) and Prothrombin Gene 20210A Mutations in Patients with Behçet's Disease
}

\author{
Aşkın Ateşa Nurşen Düzgüna Arzu Ulu ${ }^{b} \quad$ A. Olcay Aydintuğ Tiryaki ${ }^{a}$ \\ Nejat Akar ${ }^{b}$ \\ Departments of a Clinical Immunology and Rheumatology, and ${ }^{b}$ Pediatric Molecular Genetics, \\ Ankara University Faculty of Medicine, Ankara, Turkey
}

\section{Key Words}

Behçet's disease - Venous thrombosis - Factor $V$ gene 1691A mutation - Factor $V$ gene $4070 \mathrm{G}$ mutation . Prothrombin gene 20210A mutation

\begin{abstract}
Objectives: Behçet's disease (BD) is a chronic inflammatory disorder of still unknown etiology, characterized by endothelial cell injury/dysfunction and thrombosis and/ or aneurysm of large blood vessels. Thrombophilia may play a role in the pathogenesis of thrombosis in BD. The common inherited gene defects, factor $V$ (FV) 1691A (Leiden) and prothrombin (PT) 20210A, are known risk factors for thrombosis. The FV 4070G polymorphism was shown to influence circulating FV levels and to contribute to the activated protein $C$ resistance phenotype. The aim of the study was to evaluate the role of FV 1691A, FV 4070G and PT 20210A gene mutations in Turkish BD patients with and without venous thrombosis. Methods: Seventy-one patients with BD (27 with venous thrombosis) and 91 healthy subjects were included in the study. FV 1691A, FV 4070G, and PT 20210A mutations were determined by a method based on PCR-RFLP. Results: The frequency of FV 1691A heterozygous muta-
\end{abstract}

tion in BD patients with venous thrombosis $(25.9 \%)$ was significantly higher than that in healthy subjects $(8.8 \%$; $\mathrm{OR}=3.63 ; 95 \% \mathrm{Cl} 1.18-11.2$ ). Although the frequency of this mutation in patients with venous thrombosis was higher than that in the patients without venous thrombosis $(11.4 \%)$, the difference did not reach a statistically significant level ( $\mathrm{OR}=2.73 ; 95 \% \mathrm{Cl}$ 0.77-9.70). In $\mathrm{BD}$ patients with thrombosis, the frequencies of FV $4070 \mathrm{G}$ and PT 20210A were not significantly different compared to the $\mathrm{BD}$ patients without venous thrombosis and healthy subjects. Conclusions: Our results suggest that the FV 1691A, FV 4070G, and PT 20210A mutations are unlikely to play an important role in the pathogenesis of thrombosis in patients with $\mathrm{BD}$.

Copyright $(2003$ S. Karger AG, Basel

\section{Introduction}

Behçet's disease (BD) is a systemic vasculitis of unknown etiology, characterized by recurrent oral and genital ulcers and uveitis [1]. Cutaneous, articular, neurologic, intestinal, pulmonary, urogenital, and cardiovascular manifestations have also been observed [2]. The prevalence of vascular involvement such as venous or arterial

\section{KARGER \\ Fax + 41613061234 \\ E-Mail karger@karger.ch \\ www.karger.com

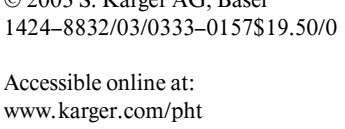

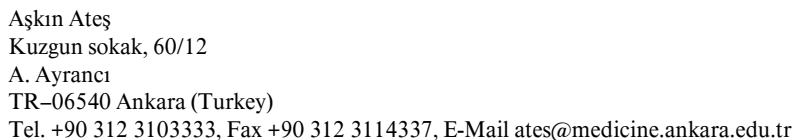


thrombosis and arterial aneurysms in $\mathrm{BD}$ is estimated to be about $25 \%$. Venous thrombosis is more common than arterial thrombosis (88 vs. 12\%). Deep and superficial venous thrombosis of the lower extremities predominates [3].

The pathogenesis of thrombosis in $\mathrm{BD}$ is not yet completely understood. The vascular endothelium has procoagulant, anticoagulant, and fibrinolytic properties. Vascular endothelial cells play a critical role in the defense against thrombosis. The pathological hallmark of BD is a nonspecific vasculitis of veins, arteries, and capillaries in all affected organs. Endothelial dysfunction due to vascular inflammation is considered to be an important factor of thrombosis. Endothelial products reflecting endothelial activation and/or injury are increased in patients with BD [4-6]. However, endothelial injury itself cannot clearly account for the hypercoagulable status of $\mathrm{BD}$, because other vasculitis syndromes do not increase the risk of thrombosis. Moreover, endothelial activation markers do not differ between BD patients with and without thrombosis. Several studies have proposed a potential mechanism to explain hypercoagulability in BD. However, no consistent primary abnormality of the coagulation, anticoagulant, or fibrinolytic systems has yet been confirmed in BD [4]. Other factors including genetic defects may be the underlying cause a prothrombotic state in BD.

Thrombophilia may play a role in the pathogenesis of thrombosis in BD. Activated protein $\mathrm{C}$ (APC) resistance is now recognized as one of the most common inherited risk factors for venous thrombosis. Most cases of APC resistance are caused by a point mutation at nucleotide 1691 in the factor V (FV) gene (arginine 506 to glutamine), referred to as the FV Leiden mutation. The mutated FVa is less sensitive to APC-mediated inactivation than normal FV [4]. Subjects heterozygous for the FV Leiden mutation are exposed to a 5- to 10-fold increased risk of thrombosis, while in homozygous subjects the thrombotic risk is increased 50- to 100-fold. It is also suggested that the Leiden mutation increases the risk of deep venous thrombosis in BD [7].

A guanine to adenine base substitution at position 20210 of the 3 -untranslated region of the prothrombin (PT) gene raises PT levels. This mutation is associated with a threefold increased risk of venous thrombosis, and has been reported to be the second most common inherited hypercoagulable state. The prevalence of heterozygous 20210 carriers varies from 1 to $5 \%$ in the healthy white population [4]. The frequency of FV 1691A and PT 20210A mutations was found to be 10.4 and $2.7 \%$, respectively, in the Turkish population $[8,9]$.
Recently, a genetic component in the FV gene that contributes to APC resistance both in the presence and absence of FV Leiden was reported. This highly conserved FV gene haplotype, called the R2 polymorphism, is characterized by an $\mathrm{A} \rightarrow \mathrm{G}$ mutation at position 4070 in exon 13 that predicts a His 1299 Arg substitution [10]. The presence of the FV $4070 \mathrm{~A} \rightarrow \mathrm{G}$ mutation has been reported in different populations including the Turkish. Akar et al. [9] reported the frequency of the FV 4070G mutation to be $8.5 \%$ in a healthy Turkish population. Previous reports on the effect of the $4070 \mathrm{G}$ mutation on the occurrence of deep vein thrombosis is controversial [11, 12]. Akar et al. [12] revealed that the FV 1691A mutation is a risk factor for thromboembolism but FV $4070 \mathrm{G}$ is not.

The aim of this study was to evaluate the role of FV Leiden, FV 4070G and PT 20210A gene mutations for the development of venous thrombosis in Turkish BD patients.

\section{Patients and Methods}

Seventy-one patients, 43 males and 28 females, fulfilling the International Study Group criteria for the diagnosis of BD [13] were included in the study. Patients were recruited from a hospital-based sample. The mean age was $35.7 \pm 9.5$ (range 17-55) years, and mean disease duration was $80 \pm 60$ (range 6-264) months in patients with BD. Ninety-one healthy subjects of the same ethnic origin (56 males and 35 females) without any familial history of thromboembolism were also included in the study as a control group. The mean age of the control group was $33.8 \pm 8.5$ years. The study was approved by the Committee on Medical Ethics of the Ankara University Faculty of Medicine, and written informed consent was obtained from all subjects after an explanation of the purpose of the study.

The detailed clinical characteristics were recorded for each patient. Patients who had recurrent oral and genital ulcers, skin lesions and positive pathergy testing were diagnosed as having mucocutaneous $\mathrm{BD}$. BD with vascular involvement described patients with venous and arterial thromboses and/or aneurysm. Isolated superficial thrombophlebitis without accompanying deep vein thrombosis was not considered as having vascular involvement, and such patients were included in the mucocutaneous group. Patients with mucocutaneous BD who had a disease duration of $<5$ years were excluded from the study as the risk of developing vascular involvement is high in the first 5 years following the diagnosis. The diagnosis of vascular involvement was made on clinical grounds by color Doppler ultrasonographic and/or angiography using computed tomographic or magnetic resonance techniques where appropriate. Patients with parenchymal lesions were defined as having neurological involvement.

DNA was extracted by conventional methods and polymerase chain reaction (PCR) of the FV gene was performed according to previously described methods using for FV 1691 G-A primers 5'-TCAGGCAGGAACAACACC-3' and 5'-GTTACTTCAAGGAACAAAATACCTGTAAAGCT-3', and FV 4070 A-G primers 5'-CAA- 
Table 1. The demographic and clinical characteristics of patient groups

\begin{tabular}{lccc}
\hline & All patients & $\begin{array}{l}\text { Patients with } \\
\text { venous thrombosis }\end{array}$ & $\begin{array}{l}\text { Patients without } \\
\text { venous thrombosis }\end{array}$ \\
\hline Number & 71 & 27 & 44 \\
Age, years & $35.7 \pm 9.5$ & $36.3 \pm 8.2$ & $35.4 \pm 10.2$ \\
Sex (male/female) & $43 / 28$ & $23 / 4 *$ & $20 / 24$ \\
Oral ulcers & $71(100 \%)$ & $27(100 \%)$ & $44(100 \%)$ \\
Genital ulcers & $63(88.7 \%)$ & $22(81.5 \%)$ & $41(93.2 \%)$ \\
Papulopustular eruption & $47(66.2 \%)$ & $19(70.4 \%)$ & $28(63.6 \%)$ \\
Erythema nodosum & $41(57.7 \%)$ & $21(77.8 \%) * *$ & $20(45.5 \%)$ \\
Positive pathergy test & $34(47.9 \%)$ & $12(63.2 \%)$ & $22(57.9 \%)$ \\
Ocular involvement & $28(39.4 \%)$ & $11(40.7 \%)$ & $17(38.6 \%)$ \\
Arthritis & $9(12.7 \%)$ & $6(22.2 \%)$ & $3(6.8 \%)$ \\
Neurologic involvement & $3(4.2 \%)$ & $2(7.4 \%)$ & $1(2.3 \%)$ \\
Superficial thrombophlebitis & $26(36.6 \%)$ & $22(81.5 \%)$ & $4(9.1 \%)$ \\
Deep vein thrombosis & $27(38.0 \%)$ & $27(100 \%)$ & \\
Inferior caval vein thrombosis & $4(5.6 \%)$ & $4(14.8 \%)$ & $1(2.3 \%)$ \\
Superior caval vein thrombosis & $3(4.2 \%)$ & $3(11.1 \%)$ & \\
Arterial involvement & $13(18.3 \%)$ & $12(44.4 \%)$ & \\
\hline
\end{tabular}

Categorical data are expressed as number of subjects with percentages in parentheses.

$* \mathrm{p}=0.001 ;{ }^{* *} \mathrm{p}<0.05$ vs. patients without venous thrombosis.

GTCCTTCCCCACAGATATA-3' and 5'-AGATCTGCAAAGAGGGGCAT-3'. Amplification was performed for 35 cycles with an annealing temperature of $57^{\circ} \mathrm{C}$ (Ericomp, USA). Amplified DNA was digested with HindIII enzyme (Promega, Madison, Wisc., USA) for FV $1691 \mathrm{G}-\mathrm{A}$, and RsaI enzyme (Promega) for FV $4070 \mathrm{~A}-\mathrm{G}$ at $37^{\circ} \mathrm{C}$ and subjected to $2 \%$ agarose gel electrophoresis $[11,14]$. The detection of the 20210A allele in the PT gene was performed according to a previously described PCR method using the primers 5'-TCTAGAAACAGTTGCCTGGC-3' (nt 19889-19908) and a mutagenic primer 5'-ATAGCACTGGGAGCATTGAAGC-3' (nt 20333-20212). The HindIII enzyme (Promega) was used to determine the mutation [15].

Comparison of means and percentages was made with the unpaired Student's $t$ test and $\chi^{2}$ test with Yates correction or Fisher's exact test, as appropriate. The associations between genotype frequency and BD or venous thrombosis are expressed as odds ratio (OR) with 95\% confidence intervals (CI).

\section{Results}

The demographic and clinical characteristics of all BD patients and the patients with or without venous thrombosis are shown in table 1 . Twenty-seven patients had venous thrombosis and 44 patients had no thrombotic events. The distribution of mutations and vascular involvement characteristics in $27 \mathrm{BD}$ patients with venous thrombosis are shown in table 2 . All patients with venous thrombosis had deep vein thrombosis of the lower extremities, and 4 had inferior vena cava and 3 superior vena cava thrombosis. Isolated caval vein thrombosis was not seen. Superficial thrombophlebitis was seen in 26 patients with BD, 22 of them also had deep vein thrombosis. Aneurysm formation, or thrombotic occlusion in pulmonary, brachial, iliac and femoral arteries were present in 13 patients. Arterial involvement was associated with venous thrombosis in 12 patients.

In patients with venous thrombosis, the frequency of male sex was significantly higher compared to the patients without venous thrombosis ( 85.2 vs. $45.5 \%$, respectively; $\mathrm{p}=0.001)$. The frequency of erythema nodosum was significantly higher in patients with venous thrombosis compared to the patients without venous thrombosis ( $77.8 \mathrm{vs.}$ $45.5 \%$, respectively; $\mathrm{p}<0.05$ ). Other demographic and clinical characteristics were found to be similar between both groups.

The genotype distribution of FV 1691A, FV 4070G and PT 20210A mutations are given in table 3. All subjects with these mutations were heterozygous carriers. Two BD patients, 1 in the venous thrombosis and 1 in the mucocutaneous group, carried both FV 1691A and PT 20210A mutations. Although the frequency of FV 1691A heterozygotes in patients with BD was higher than that in healthy subjects (16.9 vs. $8.8 \%)$, the difference did not 
Table 2. Mutation and thrombosis data of our BD patients with venous thrombosis

\begin{tabular}{|c|c|c|c|c|c|c|c|c|c|}
\hline $\begin{array}{l}\text { Patient } \\
\text { No. }\end{array}$ & $\begin{array}{l}\text { Age } \\
\text { years }\end{array}$ & Sex & $\begin{array}{l}\text { FV } \\
1691 \mathrm{~A}\end{array}$ & $\begin{array}{l}\text { FV } \\
4070 \mathrm{G}\end{array}$ & $\begin{array}{l}\text { PT } \\
20210 \mathrm{~A}\end{array}$ & DVT & CVT & A & ST \\
\hline 1 & 31 & $\mathrm{M}$ & - & - & - & + & - & + & + \\
\hline 2 & 36 & $\mathrm{M}$ & - & - & - & + & - & - & + \\
\hline 3 & 40 & $\mathrm{~F}$ & - & - & - & + & - & - & + \\
\hline 4 & 53 & $\mathrm{M}$ & - & - & - & + & - & - & + \\
\hline 5 & 38 & M & + & - & - & + & - & + & + \\
\hline 6 & 31 & $\mathrm{M}$ & - & - & - & + & - & + & + \\
\hline 7 & 38 & $\mathrm{M}$ & + & - & - & + & +1 & - & + \\
\hline 8 & 35 & $\mathrm{~F}$ & - & - & - & + & - & - & - \\
\hline 9 & 41 & $\mathrm{M}$ & - & - & - & + & $+^{2}$ & + & + \\
\hline 10 & 30 & $\mathrm{M}$ & - & - & - & + & - & + & + \\
\hline 11 & 23 & $\mathrm{M}$ & + & - & + & + & - & - & + \\
\hline 12 & 21 & M & - & - & - & + & +1 & + & + \\
\hline 13 & 28 & M & - & - & - & + & - & - & - \\
\hline 14 & 30 & $\mathrm{M}$ & - & - & - & + & - & + & + \\
\hline 15 & 34 & $\mathrm{~F}$ & - & - & + & + & - & + & + \\
\hline 16 & 36 & $\mathrm{M}$ & - & - & - & + & - & + & + \\
\hline 17 & 29 & $\mathrm{M}$ & - & - & - & + & - & - & + \\
\hline 18 & 29 & $\mathrm{~F}$ & - & - & - & + & - & - & + \\
\hline 19 & 47 & $\mathrm{M}$ & - & + & - & + & +1 & + & - \\
\hline 20 & 43 & $\mathrm{M}$ & - & - & - & + & - & - & - \\
\hline 21 & 30 & M & - & - & - & + & - & - & + \\
\hline 22 & 47 & $\mathrm{M}$ & + & - & - & + & - & - & + \\
\hline 23 & 36 & $\mathrm{M}$ & - & - & - & + & +2 & + & - \\
\hline 24 & 36 & $\mathrm{M}$ & + & - & - & + & $+^{2}$ & - & + \\
\hline 25 & 41 & $\mathrm{M}$ & + & - & - & + & +1 & - & + \\
\hline 26 & 33 & $\mathrm{M}$ & - & + & - & + & - & - & + \\
\hline 27 & 55 & $\mathrm{M}$ & + & - & - & + & - & - & + \\
\hline \multicolumn{10}{|c|}{$\begin{array}{l}\text { DVT }=\text { Deep vein thrombosis; } \mathrm{ST}=\text { superficial thrombophlebitis; } \mathrm{CVT}=\text { caval venous thrombosis; } \mathrm{A}=\text { arterial } \\
\text { lesion; } \mathrm{M}=\text { male; } \mathrm{F}=\text { female. }\end{array}$} \\
\hline
\end{tabular}

Table 3. Distribution of genetic polymorphisms in patients with Behçet's disease and healthy subjects

\begin{tabular}{lcccc}
\hline & All patients & $\begin{array}{l}\text { Patients with } \\
\text { venous } \\
\text { thrombosis }\end{array}$ & $\begin{array}{l}\text { Patients without } \\
\text { venous } \\
\text { thrombosis }\end{array}$ & $\begin{array}{l}\text { Healthy } \\
\text { subjects }\end{array}$ \\
\hline $\begin{array}{l}\text { Factor V 1691A } \\
\text { GG }\end{array}$ & $59(83.1 \%)$ & $20(74.1 \%)$ & $39(88.6 \%)$ & $83(91.2 \%)$ \\
GA & $12(16.9 \%)$ & $7(25.9 \%)$ & $5(11.4 \%)$ & $8(8.8 \%)$ \\
\hline Factor V 4070G & $66(93.0 \%)$ & $25(92.6 \%)$ & $41(93.2 \%)$ & $83(91.2 \%)$ \\
AA & $5(7.0 \%)$ & $2(7.4 \%)$ & $3(6.8 \%)$ & $8(8.8 \%)$ \\
AG & & & & \\
\hline Prothrombin 20210A & & & & \\
GG & $7(90.1 \%)$ & $25(92.6 \%)$ & $5(88.6 \%)$ & $88(96.7 \%)$ \\
GA & $7(9.9 \%)$ & $2(7.4 \%)$ & $5(11.4 \%)$ & $3.3 \%)$ \\
\hline
\end{tabular}

Data are presented as the number of subjects with percentages in parentheses. 
Table 4. The relationships between procoagulant mutations and clinical findings in patients with Behçet's disease

\begin{tabular}{|c|c|c|c|}
\hline & FV 1691A & FV 4070G & PT 20210A \\
\hline \multicolumn{4}{|c|}{ Genital ulcers } \\
\hline Present & $11(17.5 \%)$ & $5(7.9 \%)$ & $6(9.5 \%)$ \\
\hline Absent & $1(12.5 \%)$ & $0(0.0 \%)$ & $1(12.5 \%)$ \\
\hline \multicolumn{4}{|c|}{ Papulopustular eruption } \\
\hline Present & $8(17.0 \%)$ & $2(4.3 \%)$ & $3(6.4 \%)$ \\
\hline Absent & $4(16.7 \%)$ & $3(12.5 \%)$ & $4(16.7 \%)$ \\
\hline \multicolumn{4}{|c|}{ Erythema nodosum } \\
\hline Present & $9(22.0 \%)$ & $4(9.8 \%)$ & $4(9.8 \%)$ \\
\hline Absent & $3(10.0 \%)$ & $1(3.3 \%)$ & $3(10.0 \%)$ \\
\hline \multicolumn{4}{|c|}{ Positive pathergy test } \\
\hline Present & $4(11.8 \%)$ & $5(14.7 \%)$ & $3(8.8 \%)$ \\
\hline Absent & $4(17.4 \%)$ & $0(0.0 \%)$ & $2(8.7 \%)$ \\
\hline \multicolumn{4}{|c|}{ Ocular involvement } \\
\hline Present & $5(17.9 \%)$ & $2(7.1 \%)$ & $1(3.6 \%)$ \\
\hline Absent & $7(16.3 \%)$ & $3(7.0 \%)$ & $6(14.0 \%)$ \\
\hline \multicolumn{4}{|l|}{ Arthritis } \\
\hline Present & $4(44.4 \%)^{*}$ & $0(0.0 \%)$ & $0(0.0 \%)$ \\
\hline Absent & $8(12.9 \%)$ & $5(8.1 \%)$ & $7(11.3 \%)$ \\
\hline \multicolumn{4}{|c|}{ Neurologic involvement } \\
\hline Present & $0(0.0 \%)$ & $1(33.3 \%)$ & $2(66.7 \%)^{*}$ \\
\hline Absent & $12(17.6 \%)$ & $4(5.9 \%)$ & $5(7.4 \%)$ \\
\hline \multicolumn{4}{|c|}{ Superficial thrombophlebitis } \\
\hline Present & 7 (26.9\%) & $1(3.8 \%)$ & $3(11.5 \%)$ \\
\hline Absent & $5(11.1 \%)$ & $4(8.9 \%)$ & $4(8.9 \%)$ \\
\hline \multicolumn{4}{|c|}{ Arterial involvement } \\
\hline Present & $1(7.7 \%)$ & $1(7.7 \%)$ & $1(7.7 \%)$ \\
\hline Absent & $11(19.0 \%)$ & $4(6.9 \%)$ & $6(10.3 \%)$ \\
\hline
\end{tabular}

reach a statistically significant level $(\mathrm{OR}=2.11 ; 95 \% \mathrm{CI}$ 0.81-5.48). The FV 1691A mutation was detected in 7 of $27 \mathrm{BD}$ patients with venous thrombosis $(25.9 \%)$, and in 5 of $44 \mathrm{BD}$ patients without thrombosis $(11.4 \%)$. The frequency of heterozygous carriers of the FV 1691A mutation in BD patients with venous thrombosis was significantly higher compared to healthy subjects $(\mathrm{OR}=3.63$; $95 \%$ CI $1.18-11.2 ; \mathrm{p}<0.05)$. However, there was no significant difference between the BD patients with and without venous thrombosis $(\mathrm{OR}=2.73$; 95\% CI 0.77 9.70; $p=0.11$ ).

The frequency of FV 4070G heterozygotes in BD patients was similar to that in healthy controls (7.0 and
$8.8 \%$, respectively; OR $=0.79 ; 95 \%$ CI $0.25-2.52$ ). This mutation frequency in BD patients with venous thrombosis $(7.4 \%)$ was not found to be significantly different from that of BD patients without venous thrombosis $(6.8 \%)$ or healthy subjects $(\mathrm{OR}=1.09 ; 95 \% \mathrm{CI} 0.17-7.00$ and $\mathrm{OR}=$ $0.83 ; 95 \%$ CI $0.16-4.16$, respectively).

Although the frequency of PT 20210A heterozygotes in patients with BD was higher than that in healthy controls (9.9 and 3.3\%, respectively), the difference did not reach a statistically significant level $(\mathrm{OR}=3.21 ; 95 \%$ CI 0.80 12.9). This mutation was detected in 2 of $\mathrm{BD}$ patients with thrombosis $(7.4 \%)$, and in 5 of BD patients without thrombosis (11.4\%). No statistically significant difference between the BD patients with venous thrombosis and the $\mathrm{BD}$ patients without venous thrombosis $(\mathrm{OR}=0.62 ; 95 \%$ CI $0.11-3.47)$ or healthy subjects $(\mathrm{OR}=2.35 ; 95 \% \mathrm{CI}$ 0.37-14.8) in prevalence of PT 20210A mutation was obtained.

The relationships between the tested gene mutations and other clinical findings of BD are shown in table 4 . There was a significant correlation between the presence of FV 1691A mutation and arthritis (OR $=5.40 ; 95 \% \mathrm{CI}$ $1.19-24.4, \mathrm{p}<0.05)$. Although the number of the patients was very small, the PT 20210A mutation frequency was significantly higher in patients with neurologic involvement than in the patients without neurologic involvement (66.7 and 7.4\%, respectively; OR $=25.2$; 95\% CI $1.93-$ $328.4, \mathrm{p}<0.05)$. Except for these, the FV 1691A, FV 4070G and PT 20210A mutations did not show any association with other clinical characteristics, including arterial involvement and superficial thrombophlebitis.

\section{Discussion}

Although a thrombotic tendency is one of the major characteristics of $\mathrm{BD}$, the pathogenetic mechanisms leading to venous thrombosis are not yet fully understood. Most thrombotic abnormalities have been attributed to the endothelial injury secondary to vasculitis. However, endothelial injury itself cannot clearly account for the hypercoagulable status of $\mathrm{BD}$, because other vasculitis syndromes do not increase the risk of thrombosis, and the endothelial activation markers do not differ between BD patients with and without thrombosis. Recently, it has been suggested that procoagulant mutations may play a role in the development of thrombotic events in BD patients. Several groups have studied the contribution of FV 1691A (Leiden) and PT 20210A mutations to thrombotic tendency in BD patients [16-23]. However, there 
are some controversies in this issue mainly resulting from features of the study populations. To our knowledge, this is the first study to examine the association of the three common procoagulant mutations, FV 1691A, PT 20210A, and FV 4070A, with venous thrombosis in BD patients. The risk of developing vascular involvement in patients with $\mathrm{BD}$ is high in the first 5 years following diagnosis [3]. Patients without venous thrombosis who had a disease duration of $<5$ years were excluded from the present study. This approach provided a more favorable examination of the association between procoagulant mutations and development of venous thrombosis.

The prevalence of the FV 1691A mutation in BD varies from 0 to $38 \%$ [16-23]. In our study the frequency of heterozygous carriers of the FV 1691A mutation was $16.9 \%$ in all $\mathrm{BD}$ patients, $25.9 \%$ in BD patients with venous thrombosis, and $8.8 \%$ in healthy subjects. Although the frequency of the FV 1691A mutation in BD patients with venous thrombosis was found to be significantly higher than in healthy subjects, the difference between BD patients with and without venous thrombosis did not reach a statistically significant level. Previous reports on the association between the FV 1691A mutation and venous thrombosis in BD patients are controversial, with studies favoring [17, 19] or opposing [16, 18, 22, 23] this association. Verity et al. [21] reported that the FV 1691A mutation was significantly associated with ocular disease in BD patients but not with deep vein thrombosis. The association of the FV 1691A mutation with venous thrombosis in Turkish BD patients has been investigated in three studies, one reported a significant relation with thrombosis [17], whereas the others did not [20, 23]. Gül et al. [17] compared the frequency of the FV 1691A mutation in $32 \mathrm{BD}$ patients with venous thrombosis and 32 patients without venous thrombosis, and found that the presence of FV 1691A heterozygosity in patients with BD was associated with a 5.8-fold increase in the risk of venous thrombosis. However, Toydemir et al. [23] did not find a significant difference in the frequency of the FV 1691A mutation in BD patients with and without venous thrombosis. The study of Öner et al. [20] was concerned only with 5 patients with venous thrombosis, therefore, no conclusion could be drawn from this study.

The PT 20210A mutation was investigated in two large studies, one reported no increase in the frequency of the PT gene mutation [23], and the other reported a significant relation with thrombosis [24]. Gül et al. [24] reported that the heterozygous PT gene 20210A mutation was found in $31.3 \%$ of BD patients with venous thrombosis and in $3.1 \%$ of BD patients without thrombosis. In addi- tion, 3 patients with BD who had recurrent venous thrombosis, arterial thrombosis, or intracardiac thrombosis associated with the PT 20210A mutation have been described $[25,26]$. We observed no difference in the frequency of the PT gene mutation between patients with BD and control subjects ( 9.5 and 3.3\%, respectively). There was also no significant difference in the frequency of the PT 20210A mutation in BD patients with and without thrombosis (7.1 and 10.7\%, respectively).

We evaluated the thrombotic risk of the FV 4070A mutation, which to our knowledge has not been studied before in patients with BD. The frequency of this mutation was $6.0 \%$ in all $\mathrm{BD}$ patients, $3.3 \%$ in $\mathrm{BD}$ patients with venous thrombosis, $7.4 \%$ in $\mathrm{BD}$ patients without thrombosis, and $8.8 \%$ in healthy subjects. When these groups were compared with each other, the differences were not found to be statistically significant.

Although vascular disease and thrombosis are the most important features of $\mathrm{BD}$, the pathogenesis of thrombosis is not yet completely understood. Our data suggest that procoagulant mutations do not seem to play an important role in the pathogenesis of thrombosis in patients with BD. The development of thrombosis in BD patients requires additional trigger events such as other defects in the coagulation pathway, anticoagulant factors, and fibrinolysis, along with environmental factors.

\section{Acknowledgement}

This study is supported in part by Ankara University Research Foundation. 


\section{References}

1 O'Duffy JD: Behçet's disease. Curr Opin Rheumatol 1994;6:39-43.

2 Yazıcı H, Yurdakul S, Hamuryudan V: Behçet's syndrome; in Klippel JH, Dieppe PA (eds): Rheumatology, ed 2. Barcelona, Mosby, 1998, pp 26.1-26.6.

3 Koç Y, Güllü I, Akpek G, Akpolat T, Kansu E, Kiraz S, Batman F, Kansu T, Balkanci F, Akkaya S: Vascular involvement in Behçet's disease. J Rheumatol 1992;19:402-410.

4 Leiba M, Sidi Y, Gür H, Leiba A, Ehrenfeld M: Behçet's disease and thrombophilia. Ann Rheum Dis 2001;60:1081-1085.

5 Haznedaroğlu IC, Özcebe OI, Özdemir O, Çelik I, Dündar SV, Kirazlı S: Impaired haemostatic kinetics and endothelial function in Behçet's disease. J Intern Med 1996;240:181-187.

6 Düzgün N, Ayaşlıŏlu E, Tutkak H, Sahin M, Aydıntuğ O, Ölmez Ü: Plasma thrombomodulin levels in patients with Behçet's disease. Rheumatol Int 2003;23:130-133.

7 Rosendaal FR, Koster T, Vandenbroucke JP, Reitsma DP: High risk of thrombosis in patients homozygous for factor V Leiden (activated protein C resistance). Blood 1995;85: 1504-1508.

8 Akar N, Akar E, Dalgın G, Sözüöz A, Ömürlü $\mathrm{K}$, Cin S: Frequency of factor V $(1691 \mathrm{G} \rightarrow \mathrm{A})$ mutation in Turkish population. Thromb Haemost 1997;78:1527-1528.

9 Akar N, Mısırlıŏlu M, Akar E, Avcu F, Yalçın A, Sözüöz A: Prothrombin gene 20210 G-A mutation in the Turkish population. Am J Hematol 1998;58:249.

10 Faioni EM, Franchi F, Bucciarelli P, Margaglione M, De Stefano V, Castaman G, Finazzi G, Mannucci PM: Coinheritance of the HR2 haplotype in the factor $\mathrm{V}$ gene confers an increased risk of venous thromboembolism to carriers of factor V R506Q. Blood 1999;94 3062-3066.
11 Alhenc-Gelas M, Nicaud V, Gandrille S, van Dreden P, Amiral J, Aubry ML, Fiessinger JN, Emmerich J, Aiach M: The factor V gene A4070G mutation and the risk of venous thrombosis. Thromb Haemost 1999;81:193197.

12 Akar N, Akar E, Yilmaz E: Factor V (His 1299 Arg) in Turkish patients with venous thromboembolism. Am J Hematol 2000;63:102-103.

13 International Study Group for Behçet's Disease: Criteria for diagnosis of Behçet's disease. Lancet 1990;335:1078-1080.

14 Gandrille S, Alhenc-Gelas M, Aiach M: A rapid screening method for the factor $\mathrm{V}$ Arg506 $\rightarrow$ Gln mutation. Blood Coagul Fibrinolysis 1995;6:245-248.

15 Poort SR, Rosendaal FR, Reitsma PH, Bertina $\mathrm{RM}$ : A common genetic variation in the $3^{\prime}$-untranslated region of the prothrombin gene is associated with elevated plasma prothrombin levels and an increase in venous thrombosis. Blood 1996;88:3698-3703.

16 Mader R, Ziv V, Adawi M, Mader R, Lavi I: Thrombophilic factors and their relation to thromboembolic and other clinical manifestation in Behçet's disease. J Rheumatol 1999;26: 2404-2408.

17 Gül A, Özbek U, Öztürk C, Inanç M, Koniçe M, Özçelik T: Coagulation factor V gene mutation increases the risk of venous thrombosis in Behçet's disease. Br J Rheumatol 1996;35: 1178-1180.

18 Lesprit P, Weschler B, Piette JC, Du-Boutin LT, Godeau P, Alhenc-Gelas M, Aiach M: Activated protein $\mathrm{C}$ resistance caused by factor $\mathrm{V}$ Arg506Gln mutation has no role in thrombotic manifestations of Behçet's disease. Ann Rheum Dis 1995;54:860.
19 Mammo L, Al-Dalaan A, Bahabri SS, Saour JN: Association of factor V Leiden with Behçet's disease. J Rheumatol 1997;24:21962198.

20 Öner AF, Gürgey A, Gürler A, Mesci L: Factor $\mathrm{V}$ Leiden mutation in patients with Behçet's disease. J Rheumatol 1998;25:496-498.

21 Verity DH, Vaughan RW, Madanat W, Kondeatis E, Zureikat H, Fayyad F, Kanawati CA Ayesh I, Stanford MR, Wallace GR: Factor V Leiden mutation is associated with ocular involvement in Behçet's disease. Am J Ophthalmol 1999; 128:352-356.

22 Espinosa G, Font J, Tassies D, Vidaller A, Deulofeu R, Lopez-Soto A, Cervera R, Ordinas A, Ingelmo M, Reverter JC: Vascular involvement in Behçet's disease: Relation with thrombophilic factors, coagulation activation, and thrombomodulin. Am J Med 2002;112:37-43.

23 Toydemir PB, Elhan AH, Tükün A, Toydemir R, Gürler A, Tüzüner A, Bökesoy I: Effects of factor V gene G1691A, methylenetetrahydrofolate reductase gene $\mathrm{C} 677 \mathrm{~T}$, and prothrombin gene G20210A mutations on deep venous thrombogenesis in Behçet's disease. J Rheumatol 2000;27:2849-2854.

24 Gül A, Aslantas B, Tekinay T, Koniçe M, Özçelik T: Procoagulant mutations and venous thrombosis in Behçet's disease. Rheumatology 1999;38:1298-1299.

25 Salvarani C, Calamia K, Silingardi M, Ghirarduzzi A, Olivieri I: Thrombosis associated with the prothrombin $\mathrm{G} \rightarrow \mathrm{A} 20210$ mutation in Behçet's disease. J Rheumatol 2000;27:515-516.

26 Vaya A, Forner MJ, Estelles A, Villa P, Mira Y, Ferrando F, Garcia Fuster JM, Oliver V, Aznar $\mathrm{J}$ : Intracardiac thrombosis in a case of Behçet's disease associated with the prothrombin 20210G-A mutation. Haematologica 2000;85: 425-428. 